\title{
Assessment of Outdoor and Indoor Background Gamma Radiation, the Annual Effective Dose and Excess Lifetime Cancer Risk in Birjand,
}

\section{Iran}

\author{
Hassan Zarghani, ${ }^{1}$ and Reza Jafari1 ${ }^{1,}$ \\ ${ }^{1}$ School of Paramedical, Birjand University of Medical Sciences, Birjand, IR Iran \\ "Corresponding author: Reza Jafari, School of Paramedical, Birjand University of Medical Sciences, Birjand, IR Iran. Tel: +98-9158625471, E-mail: rvzreza@gmail.com
}

Received 2016 July 17; Revised 2016 August 24; Accepted 2016 August 28.

\begin{abstract}
Background: The health implication of exposure to gamma radiation in the outdoor and indoor environments has become a major concern worldwide.

Methods: This study was conducted in the city of Birjand where three stations and buildings were randomly selected to measure the background radiation in outdoor and indoor places; for this purpose, GM detector (X5C plus) was used. All dose rates on the display of the survey meter were recorded, and the mean of all data in each station and buildings was computed and taken as the measured dose rate of that particular station.

Results: The average dose rate of background radiation was $71.8 \mathrm{nSv} / \mathrm{h}$ for outdoor and $82.0 \mathrm{nSv} / \mathrm{h}$ for indoor environments, and the maximum and minimum dose rates were $79.6 \mathrm{nSv} / \mathrm{h}$ and $61.7 \mathrm{nSv} / \mathrm{h}$ for outdoor measurements and $112.9 \mathrm{nSv} / \mathrm{h}$ and $70.8 \mathrm{nSv} / \mathrm{h}$ for indoor measurements, respectively.

Conclusions: The results revealed that the annual effective dose is $0.49 \mathrm{mSv}$, which is similar to that of the global level (0.48 mSv). The estimated excess lifetime cancer risk was $1.715 \times 10^{-3}$, which was high compared to the world average value of $0.25 \times 10^{-3}$.
\end{abstract}

Keywords: Gamma Radiation, Indoor and Outdoor Environment, Dose Rate, Annual Effective Dose and Excess Lifetime Cancer Risk

\section{Background}

We are continuously exposed to ionizing radiation. Background radiation emanates from primordial, cosmogenic and anthropogenic sources. Primaries are present in the earth's crust and exist all over the environment, including the human body itself (1). Cosmogenic radionuclides are born when cosmic radiations that are highly energetic and come from the sun and galactic radiation strike to the atmosphere, producing secondary radiation and uncharged particles such as protons, neutrons, pions and low-Z nuclei. In turn, the secondary particles produce cascade particles in the atmosphere (1-3). Human body irradiation from the external sources is largely due to radionuclides in uranium and thorium series and potassium-40 and their decay products that emit gamma radiation (1, 4). These radionuclides make up the earth and our building materials, which are common in rocks and soils, water, plants and air $(4,5)$. The radioactive radon gas is one of the decay products of these series. Background radiation causes nearly $80 \%$ of annual total radiation dose that a person is exposed to, which is $2.4 \mathrm{mSv}$ per person. About $54 \%$ of the total external dose originates from K-40, Ra-226 and Ra-228 received by the public $(6,7)$. One of the main determinants of the background radiation is soil radioactiv- ity concentration (8). Terrestrial radiation variation is typically larger than that of cosmic radiation (4).

The produced particles interact with the deoxyribonucleic acid (DNA) or produce free radicals. These free radicals travel to the DNA and lead to a change and breakage of chemical bonds, causing biological effects (3).

Anthropogenic sources produced from human activities, coming from the nuclear weapons testing in the atmosphere are the main man-made contribution to the environmental exposure of the world's population (9). The ubiquitous form of irradiation is background radiation, so estimating the health risk of gamma radiation is highly important in health physics (10).

The mean annual global effective dose due to natural radiation sources has determined to be $2.4 \mathrm{mSv}$ by the United Nations scientific committee on the effects of atomic radiation (UNSCEAR). A place is exposed to high levels of natural radiation (HLNR) if its natural radiation dose rate rises up to $10 \mathrm{mSv}$ y-1. Therefore, environmental gamma radiation has been measured in many areas of the world, and the map of natural radiation of these areas has been plotted (11). 


\section{Objectives}

The aim of this study was to present the background indoor and outdoor radiation dose rates and estimate the annual effective dose and excess cancer risk to the residents of Birjand.

\section{Methods}

The study area was the city of Birjand, located in the Eastern part of Iran, with a total population of 240,894 $\left(32^{\circ} 52^{\prime} \mathrm{N} 59^{\circ} 12^{\prime} \mathrm{E}\right)$ as shown in Figure 1. For measurement purposes, the map of the sites was divided into five segments as North, East, South, West and center. To measure the outdoor and indoor background radiation, three stations and buildings were randomly selected. For each measurement, the device was placed on an aluminum holder at one meter above the ground level for half an hour to avoid the effects of the ground and buildings on the outdoor and from the walls to satisfy the criteria of the indoor environment. Preferentially, the ground level was grassy. Readings were obtained in the middle of the day. Background dose equilibrium measurements rate was done in the first sixmonth of 2016, and background dose rate was read every minute in each station.

For measurement purposes, similar and common masonry buildings were selected, and GM detector (X5C plus), calibrated by the manufacturer for a period of two years, was used. All dose rates on the display of the survey meter were recorded, and the mean of all data in each station and buildings was computed and taken as the measured dose rate of that particular station. The annual effective dose of background radiation was estimated as follows (12):

$E=\left(D_{\text {out }} \times O F_{\text {out }}+D_{\text {in }} \times O F_{\text {in }}\right) \times T \times f$

Where $\mathrm{E}(\mathrm{nSv})$ is annual effective dose, $\mathrm{D}_{\text {out }}$ and $\mathrm{D}_{\text {in }}$ $(\mathrm{nSv} / \mathrm{h})$ are mean outdoor and indoor absorbed dose rates, $\mathrm{T}$ (hour) is time to convert from year to hour (24 hours $\times$ $365.25), \mathrm{OF}_{\text {out }}$ and $\mathrm{OF}_{\text {in }}$ are outdoor and indoor occupancy factors ( $20 \%$ and $80 \%$ for outdoor and indoor, respectively) and $\mathrm{f}$ is conversion coefficient ( 0.7 for adults) reported by The United Nation scientific committee on the effect of atomic radiation (UNSCEAR) to convert absorbed dose in the air to the effective dose (13).

It is necessary to measure the excess lifetime cancer risk due to gamma radiation (14). Based on the annual effective dose, excess lifetime cancer risk was calculated as follows (8):

$$
\begin{aligned}
& \text { Excess lifetime cancer risk } \\
& =E \times \text { mean duration of life }(D L) \\
& \quad \times \text { risk factor }(R F)
\end{aligned}
$$

Where $\mathrm{E}$ is the annual effective dose, $\mathrm{DL}$ is duration of life (70 years), and $\mathrm{RF}$ is the risk factor $\left(\mathrm{Sv}^{-1}\right)$ or fetal cancer risk per sievert. The value of 0.05 for the public exposure was used by the ICRP (international commission on radiological protection) for stochastic effects (15).

\section{Results}

The mean dose rates of outdoor and indoor background radiation, the corresponding effective dose rates and excess lifetime cancer risk in five parts of Birjand are summarized and presented in Table 1. Based on the results, the average dose rate of background radiation was $71.8 \mathrm{nSv} / \mathrm{h}$ for outdoor and $82.0 \mathrm{nSv} / \mathrm{h}$ for indoor environments, and the maximum and minimum dose rates were $79.6 \mathrm{nSv} / \mathrm{h}$ and $61.7 \mathrm{nSv} / \mathrm{h}$ for outdoor measurements, and $112.9 \mathrm{nSv} / \mathrm{h}$ and $70.8 \mathrm{nSv} / \mathrm{h}$ for indoor measurements, respectively.

Using Equation 1 and the dose rates of background radiation (indoor and outdoor), the estimated annual effective dose of adults in birjand was calculated as follows:

$\mathrm{E}=(71.8 \times 0.2+82.0 \times 0.8) \times 8766 \times 0.7=0.49 \mathrm{mSv} / \mathrm{y}$

Using Equation 2, excess lifetime cancer risk was calculated as follows:

Excess lifetime cancer risk $=0.49 \times 70 \times 0.05=$ $1.72 \times 10^{-3}$

\section{Discussion}

GM detector (X5C plus) was used to obtain the results of this study. The results obtained by this detector revealed that the mean outdoor and indoor dose rates in the selected areas were about 71.8 and $82.0 \mathrm{nSv} / \mathrm{h}$, respectively. These values were mainly because of the materials of the construction in indoor exposure and from terrestrial radionuclides that existed at trace levels in the soil and because of cosmic rays in outdoor exposure (12). In some cases, the outdoor data in this study was lower than the mean values from the other cities in Iran such as Isfahan (137 nSv/h), Lorestan province (113 nSv/h), Gilan province $(94 \mathrm{nSv} / \mathrm{h})$, and Oromeih $(154 \mathrm{nSv} / \mathrm{h})$. Moreover, in some cases, it was higher than that of the other cities in Iran such as Bushehr (51.8 nSv/h), Chabok sar (71 nSv/h), Kela Chay (65 $\mathrm{nSv} / \mathrm{h})$, and Pareh Sar $(67 \mathrm{nSv} / \mathrm{h})(10,11,16)$. The lowest values in the world are in Cyprus, Iceland, Egypt, the Netherlands and the United Kingdom, all of which the values were less than $40 \mathrm{nSv} / \mathrm{h}$. However, Australia, Malaysia, and Portugal had the highest values, greater than $80 \mathrm{nSv} / \mathrm{h}$. The lowest indoor values were found in New Zealand, Iceland and the United States, which were below $40 \mathrm{nSv} / \mathrm{h}$, and the highest values were found in Hungary, Malaysia, China, Albania, 


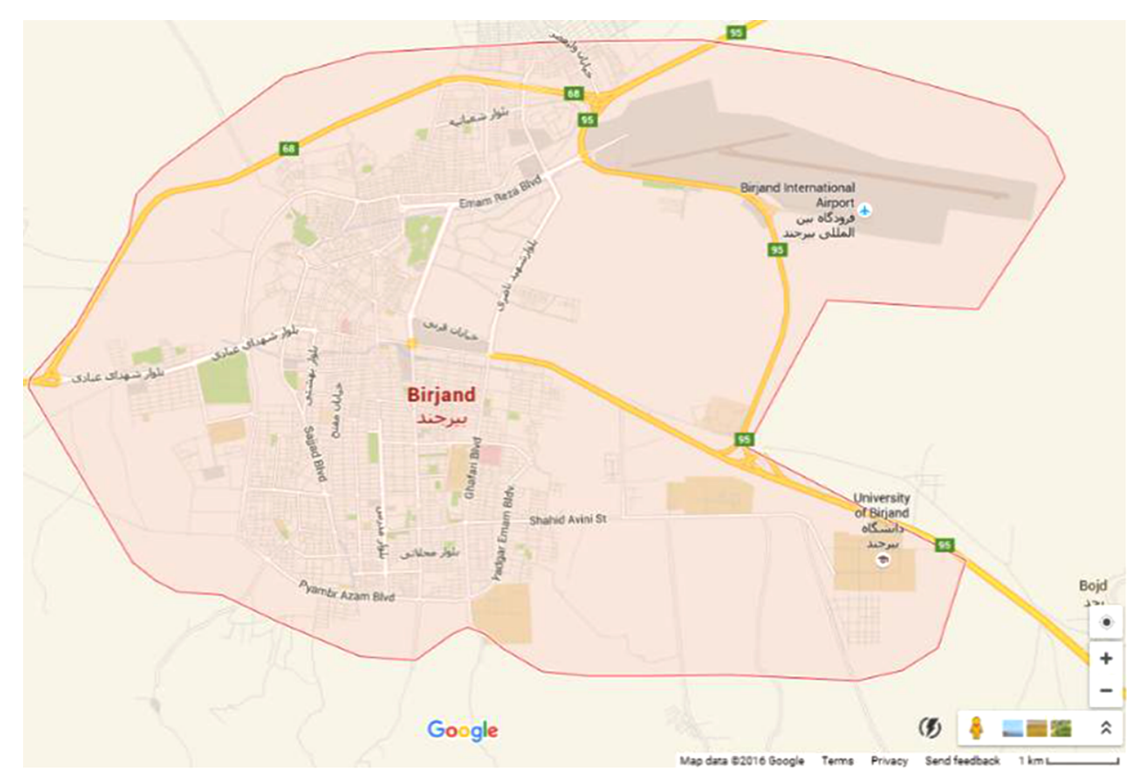

Figure 1. Partial Map of the Indoor and Outdoor Background Radiation (Google Map)

Table 1. The Average Outdoor and Indoor Background Dose Rates, Achieved Effective Dose, and Excess Lifetime Cancer Risk in the Selected Parts of Birjand

\begin{tabular}{|c|c|c|c|c|c|c|}
\hline Segment & $\begin{array}{l}\text { Average Indoor Dose Rate } \\
(\mathbf{n S v} / \mathbf{h})\end{array}$ & Range & $\begin{array}{l}\text { Average Outdoor Dose Rate } \\
(\mathbf{n S v} / \mathbf{h})\end{array}$ & Range & Effective Dose Rate (mSv/y) & $\begin{array}{l}\text { Excess Lifetime Cancer Risk } \\
\qquad\left(\times 10^{-3}\right)\end{array}$ \\
\hline North & 70.77 & $46-114$ & 75.81 & $31-140$ & 0.44 & 1.54 \\
\hline South & 75.15 & $31-154$ & 62.47 & $31-95$ & 0.45 & 1.58 \\
\hline East & 79.70 & $30-277$ & 79.60 & $38-138$ & 0.49 & 1.72 \\
\hline Center & 112.88 & $47-280$ & 65.55 & $30-138$ & 0.63 & 2.21 \\
\hline West & 79.00 & $30-143$ & 61.77 & $31-97$ & 0.46 & 1.61 \\
\hline
\end{tabular}

Portugal, Australia, Italy, Spain, Sweden, and Iran (greater than $95 \mathrm{nSv} / \mathrm{h}$ ), which might be due to the extensive use of stone or masonry materials in buildings (12). The results revealed that the effective dose due to background radiation in Birjand was similar to that of the global level. As reported by the UNSCEAR, environmental gamma radiation average for adults is $0.48 \mathrm{mSv}$ worldwide, and the individual country results were within the $0.3-0.6 \mathrm{mSv}$ range. The values are about 10\% and 30\% higher for children and infants (12).

The excess lifetime cancer risk which is $1.715 \times 10^{-3}$ is high as compared to the world average value of $0.25 \times 10^{-3}$ (12). This is due to terrestrial nuclear radiation.

\subsection{Conclusion}

To evaluate the health hazards, it is important to determine background radiation level. The indoor and outdoor dose rates, and the annual effective dose and excess life- time cancer risk to the residents were measured. The average dose rates of background radiation were $71.8 \mathrm{nSv} / \mathrm{h}$ for outdoor and $82.0 \mathrm{nSv} / \mathrm{h}$ for indoor environments. The annual effective dose was $0.49 \mathrm{mSv}$, and the estimated excess lifetime cancer risk was $1.715 \times 10^{-3}$. The results were similar compared to global levels.

\section{Acknowledgments}

The authors are thankful to Birjand University of Medical Sciences for assistance and financial support.

\section{Footnotes}

Authors' Contribution: Reza Jafari, the co-supervisor and implementation of the project; and Hassan Zarghani was the supervisor. 
Financial Disclosure: The authors declare that no competing interest is pertinent to this paper.

Funding/Support: This study was financially supported by a grant No. 4210 from Birjand University of Medical Sciences (BUMS).

\section{References}

1. UNSCEAR . Sources and effects of ionizing radiation, annex B: exposure of the public and workers from various sources of radiation. New York: United Nations Scientific Committee on the Effect of Atomic Radiations; 2008

2. Farai IP, Vincent UE. Out-door radiation level measurement in Abeokuta, Nigeria, by thermoluminescent dosimetry. Nigerian $J$ Physic. 2007;18(1) doi:10.4314/njphy.v18i1.38091.

3. Franklin AA, Daniel AF. Assessment of background Gamma radiation level in farmlands in ethiope east local government area of delta state, Nigeria. Nigerian J Physic. 2014;25(2):85-91.

4. Ononugbo CP, Avwiri GO, Tutumeni G. Estimation of indoor and outdoor effective doses from gamma dose rates of residential building in Emelogu village in rivers state, Nigeria. Inter Res J Pure Applied Physic. 2015;3(2):18-27.

5. Tzortzis M, Tsertos H, Christofides S, Christodoulides G. Gamma radiation measurements and dose rates in commercially-used natural tiling rocks (granites). J Environ Radioact. 2003;70(3):223-35.

6. Mortazavi SMJ. High background radiation areas of Ramsar, Iran. Kyoto, Japan: Kyoto University; 2002.

7. Mahur AK, Kumar R, Sonkawade RG, Sengupta D, Prasad R. Measurement of natural radioactivity and radon exhalation rate from rock samples of Jaduguda uranium mines and its radiological implications. Nucl Instrum Methods Phys Res B. 2008;266(8):1591-7.
8. Taskin H, Karavus M, Ay P, Topuzoglu A, Hidiroglu S, Karahan G. Radionuclide concentrations in soil and lifetime cancer risk due to gamma radioactivity in Kirklareli, Turkey. J Environ Radioact. 2009;100(1):49-53. doi: 10.1016/j.jenvrad.2008.10.012. [PubMed: 19038480]

9. Charles M. UNSCEAR report 2000: sources and effects of ionizing radiation. United Nations Scientific Comittee on the Effects of Atomic Radiation. J Radiol Prot. 2001;21(1):83-6. [PubMed:11281539].

10. Mahmoud Pashazadeh A, Aghajani M, Nabipour I, Assadi M. Annual effective dose from environmental gamma radiation in Bushehr city. J Environ Health Sci Eng. 2014;12(1):4. doi: 10.1186/2052-336X-12-4. [PubMed: 24393421].

11. Basirjafari S, Aghayari S, Poorabas SM, Moladoust H, Asadinezhad M. Assessment of outdoor gamma radiation dose rates in 49 cities of Guilan province, IRAN. Iran J Med Physic. 2014;11(1):168-74.

12. United Nations Scientific . Committee on the Effects of Atomic Radiation ANNEX B: Exposures from natural radiation sources, sub subsection IIC2.; 2000

13. United Nations . Scientific committee on the effects of atomic radiation sources and effects of ionizing radiation: Sources. 1. United $\mathrm{Na}$ tions Publications; 2000.

14. Rashed-Nizam QM, Rahman MM, Kamal M, Chowdhury MI. Assessment of radionuclides in the soil of residential areas of the Chittagong metropolitan city, Bangladesh and evaluation of associated radiological risk. J Radiat Res. 2015;56(1):22-9. doi: 10.1093/jrr/rru073. [PubMed: 25237039].

15. International Commission on Radiological Protection . ICRP publication 60: 1990 recommendations of the international commission on radiological protection. 60. Elsevier Health Sciences; 1991.

16. Gholami M, Mirzaei S, Jomehzadeh A. Gamma background radiation measurement in Lorestan province, Iran. Iran J Rad Res. 2011;9:89-93. 